\title{
Potential distribution of threatened Leptopelis spp. (Anura, Arthroleptidae) in Ethiopia derived from climate and land-cover data
}

\author{
Frank Weinsheimer ${ }^{1}$, Abebe A. Mengistu ${ }^{2}$, Dennis Rödder ${ }^{3, *}$ \\ ${ }^{1}$ Herpetology Department, Zoologisches Forschungsmuseum Alexander Koenig, Adenauer Allee 160, 53113 Bonn, Germany \\ ${ }^{2}$ Department of Environmental Sciences, Institute of Biogeography, University of Basel, Klingelbergstrasse 27, \\ 4056 Basel, Switzerland \\ ${ }^{3}$ Biogeography Department, Trier University, Am Wissenschaftspark 25-27, 54296 Trier, Germany
}

\begin{abstract}
Ethiopia harbours 9 species of threatened amphibians, all of which inhabit the highlands. Over the last decades, there has been a rapid increase in deforestation and habitat degradation in Ethiopia, with the result that the last undisturbed refuges for forest-dwelling anurans in the mountain areas have shrunk noticeably, especially outside of protected areas. In the present study, we used a maximum entropy ecological niche modelling approach to model the potential distribution of 2 poorly known Leptopelis species. The models were derived from climate and land cover data at known occurrences of the species (i.e. data from a number of natural history museums). These models can be used to select the priority areas most critical for future protection and may guide further field surveys to accelerate the discovery of unknown populations.
\end{abstract}

KEY WORDS: Ecological niche modeling $\cdot$ Maxent $\cdot$ Threatened species $\cdot$ Amphibia $\cdot$ Biodiversity hotspot

Resale or republication not permitted without written consent of the publisher

\section{INTRODUCTION}

Habitat loss and degradation are by far the greatest threat of amphibians, affecting $63 \%$ of all species (Stuart et al. 2004, 2008). These factors are also at work in Ethiopia, where political, socio-economic and cultural pressures have reduced the historical forested areas to a fraction of their former size, comprising a decrease of 96.4 to $97 \%$ (e.g. McCann 1999, Dessie \& Kleman 2007, Dessie \& Christiansson 2008). In the late 19th century, forests covered $65 \%$ of Ethiopian's lowlands and $90 \%$ of the highlands. Currently, only $2.2 \%$ of its lowland forests and $5.6 \%$ of its highland forests are still intact (FAO 2000). Nationwide, this means an annual loss of 163000 ha of forestland (Reusing 1998). Within one of Ethiopia's biodiversity hotspots, the south central Rift Valley, forest cover declined from $16 \%$ in 1972 to $2.8 \%$ in 2000 (Dessie \& Kleman 2007).
Of the 65 to 70 recognised amphibian species known from Ethiopia (AmphibiaWeb 2009, Frost 2009), $40 \%$ are endemic (Evangelista et al. 2008). Of these endemic species, 9 species are listed by the IUCN (2009) as threatened: Afrixalus clarkei (vulnerable, VU), A. enseticola (VU), Altiphrynoides malcomi (endangered, EN), Altiphrynoides osgoodi (VU), Balebreviceps hillmani (EN), Ericabatrachus baleensis (EN), Leptopelis ragazzii (VU), L. susanae (EN) and L. vannutellii (VU). With the exception of $A$. clarkei, which occurs at altitudes down to $820 \mathrm{~m}$ (Largen \& Schiøtz 2004), all other species are true highland forms, occurring above altitudes of $1500 \mathrm{~m}$. Therefore, unfortunately, the ranges of all threatened species are restricted to the Ethiopian highlands (Stuart et al. 2008), which show a higher rate of deforestation than lowland forests (Dessie \& Kleman 2007, Dessie \& Christiansson 2008).

In this study, we evaluated the availability of suitable habitat of threatened Ethiopian tree frogs Leptopelis 
ragazzii and $L$. vannutelli, 2 species strictly associated with undisturbed highland forest, to identify areas that may harbour additional populations of both species and to assess the level of threat to these populations from human-induced deforestation.

Leptopelis ragazzii is a poorly known species that is restricted to the central Ethiopian plateau and is strictly associated with montane forest at altitudes between 1930 and $3010 \mathrm{~m}$ a.s.l. (Largen 1977, Stuart et al. 2008). It is a medium-sized (27.9 to $49.5 \mathrm{~mm}$ snout-vent length, SVL), arboreal species. L. vannutellii inhabits dense, humid tropical deciduous forest in south-western Ethiopia at elevations of 1500 to $2200 \mathrm{~m}$ a.s.l. (Largen 1977). It resembles L. ragazzii in size (27.0 to $45.3 \mathrm{~mm}$ SVL) and overall appearance (Fig. 1), but is associated with more submontane forests characterised by the presence of Aningeria adolfi-fredericii (Sapotaceae) and Polyscias ferruginea (Araliaceae) (Largen 1977). L. vannutellii is apparently more strictly arboreal than any other Leptopelis sp., and males have never been observed calling from the ground (Largen

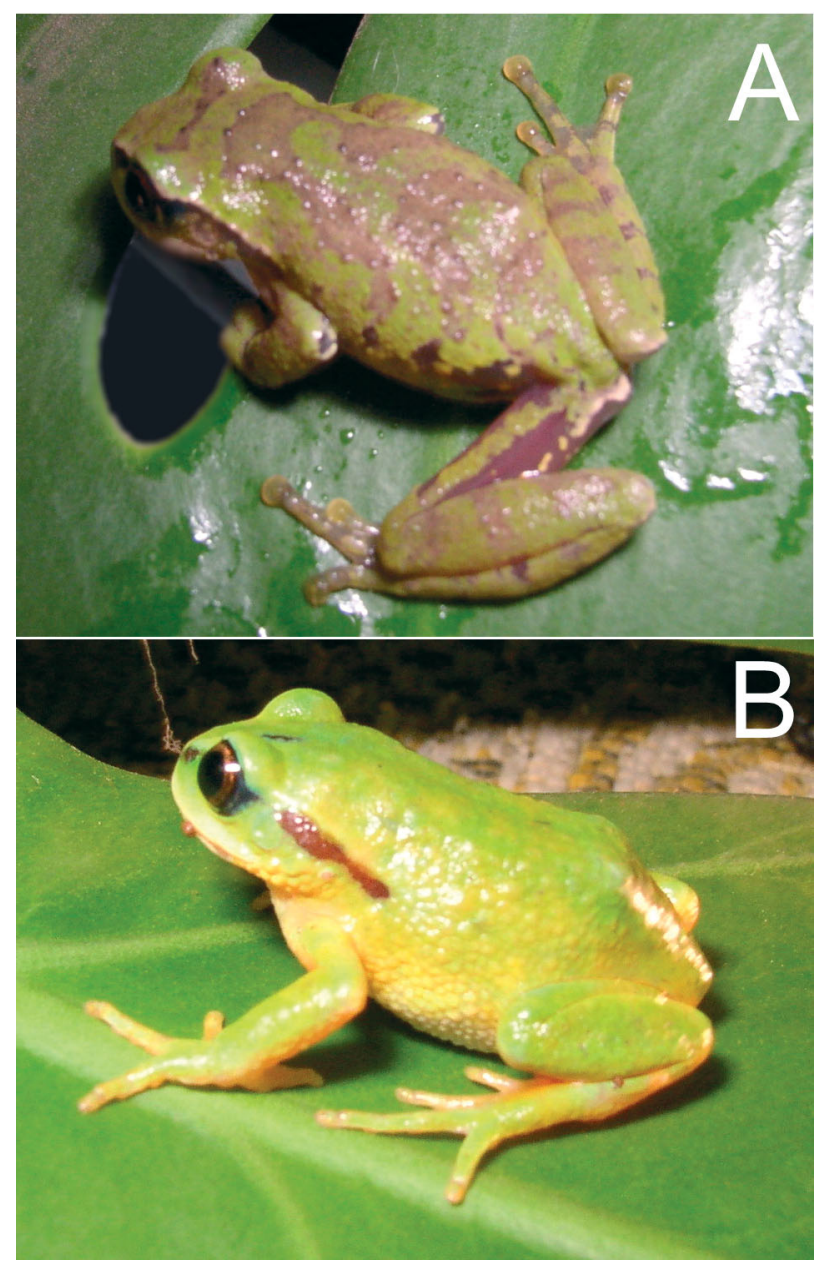

Fig. 1. (A) Leptopelis susanae and (B) L. ragazzii. Photos by S. Schick and S. Lötters
\& Schiøtz 2004). Thus, it is more dependent on dense vegetation and, like $L$. ragazzii, it does not survive in degraded habitats. Fig. 2 illustrates the distributions of both studied species, following Largen \& Schiøtz (2004).

The combination of species distribution modelling (SDM) and land cover layers provides the tools not only to incorporate what we know of the environmental conditions necessary for survival of a species (e.g. temperature and precipitation requirements), but also allows us to refine these predictions without knowledge of the microhabitat requirements for the ecology of each species. This bridges the gap between talking about the potential ecological niche to the fulfilled ecological niche, a real-world tool for conservation biologists in their efforts to assess and protect threatened species.

\section{MATERIALS AND METHODS}

Species records. In total, 12 records of Leptopelis ragazzii and 8 of $L$. vannutellii with a sufficient spatial resolution to assign them to unique grid cells of 30 arc seconds were available through literature surveys (Largen 1977, Schick 2005), the Global Biodiversity Information Facility (GBIF; www.gbif.org), HerpNet databases (www.herpnet.org) and personal observations (S. Lötters, S. Schick pers. comm.). If necessary, the BioGeoMancer (http://bg.berkeley.edu/latest/) was used for georeferencing. The accuracy of coordinates processed was assessed with DIVA-GIS by comparing the information provided with the records with locality (county, city) and elevation data (Hijmans et al. 1999, 2001). Expert maps of the distributions of the reviewed anurans were obtained from Largen \& Schiøtz (2004). Additionally, we present 2 new records of L. susanae provided by S. Lötters and S. Schick (pers. comm.).

Climate data, land cover data and protected area network. Information on current climate was obtained from the Worldclim database, version 1.4, which is derived from weather conditions recorded between 1950 and 2000 with a grid cell resolution of 30 arc seconds (Hijmans et al. 2005a; www.worldclim.org). Climate surfaces provided by Worldclim were created by interpolation of observed climate at weather stations using a thin-plate smoothing spline, whereby latitude, longitude and elevation were used as independent variables using ANUCLIM (Hutchinson 1995, 2004). A total of 19 bioclimatic variables is available (Nix 1986, Hijmans et al. 2005b). However, inclusion of too many variables in SDMs may cause 'over-fitting' problems (Beaumont et al. 2005, Heikkinen et al. 2006). Therefore, for model computation, we selected the 'annual 


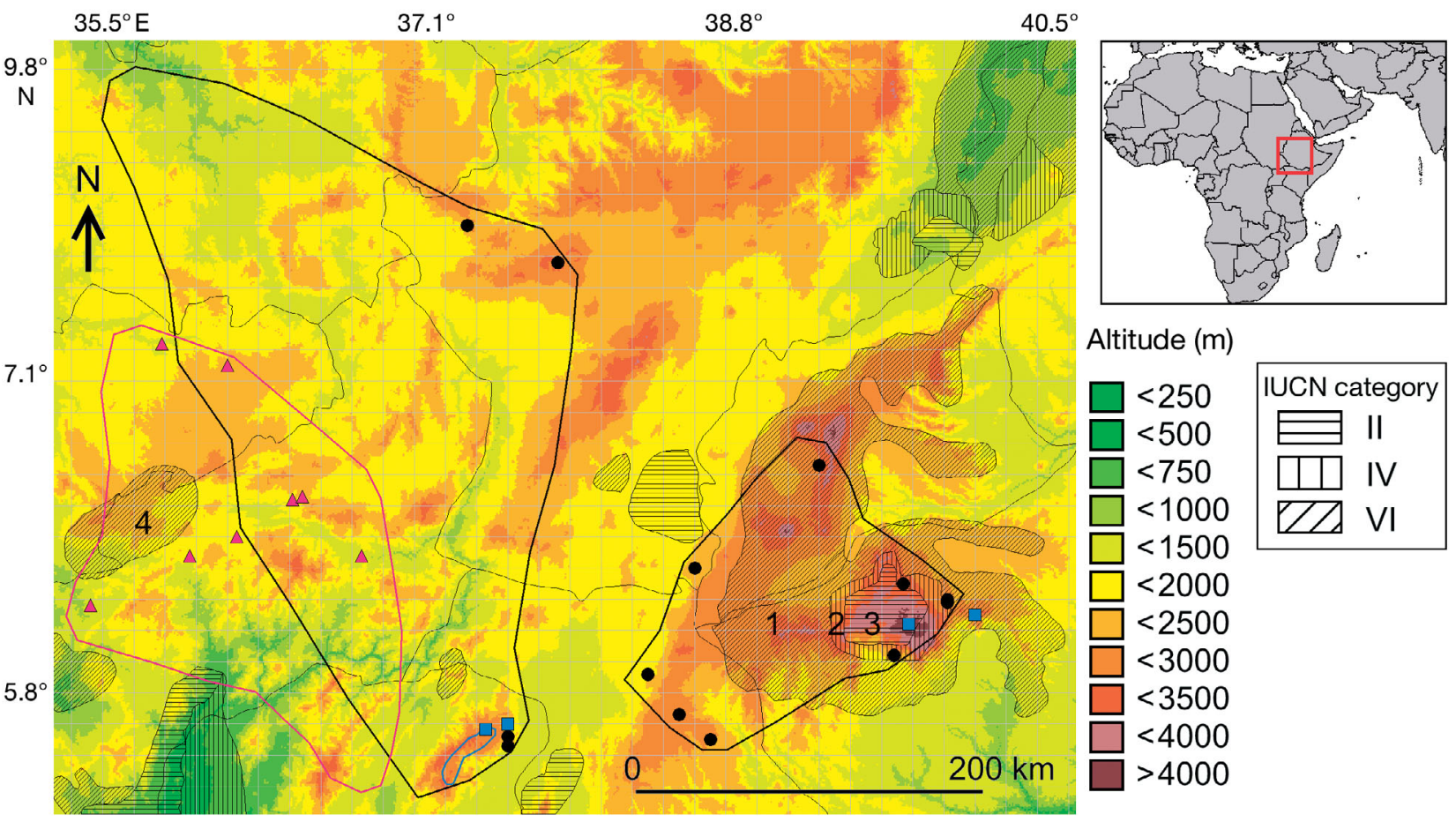

Fig. 2. Leptopelis ragazzii, L. vannutellii and L. susanae. Altitudinal distribution of L. ragazzii (black dots), L. vannutellii (pink triangles) and L. susanae (blue squares) and corresponding coverage with the protected area network. The distributions of the species assumed by Largen \& Schiøtz (2004) are indicated as polygons in the corresponding colours. $1=$ Bale Controlled Hunting Area; 2 = Bale Wildlife Reserve; 3 = Bale Mountains National Park; $4=$ Controlled hunting area of Mizan-Teferi. IUCN categories are as follows: II, areas focusing on protection and conservation of whole ecosystems; IV, areas that are actively managed to primarily protect particular species and habitats; VI, protected areas with sustainable use of natural resources

mean temperature', 'mean maximum temperature of the warmest quarter', 'mean minimum temperature of the coldest quarter', 'annual precipitation', 'mean precipitation of the wettest quarter', and 'mean precipitation of the driest quarter'. These variables characterise the availability of water and energy throughout the year and are suitable for distribution modelling (Carnaval \& Moritz 2008, Rödder \& Dambach 2009).

Land cover data was obtained from the Global Land Cover 2000 database (http://bioval.jrc.ec.europa.eu/ products/glc2000/glc2000.php). In order to facilitate interpretation, we reclassified the original land cover categories as follows (original categories given in parentheses): 'Tree cover' (categories 1 and 3), 'Mosaic of tree cover and other natural vegetation' (category 9), 'Tree cover / Crop land mosaic' (category 14), 'Shrub cover' (categories 11 and 12), and 'Other' (all other categories that exhibit strong human impacts and are deemed to be unsuitable for these pristine habitat species). Areas labelled as 'Tree cover' are covered with undisturbed broadleaved deciduous or evergreen woodland, with crown cover between 15 and $100 \%$. 'Mosaic of tree cover and other natural vegetation' regions are mainly covered by closed trees with a crown cover of more than $60 \%$. The vegetative cover in this category is characterised by the presence of (semi)natural vegetation. The category 'Tree cover/ Crop land' is composed of primarily vegetated areas containing more than $4 \%$ vegetation during at least $2 \mathrm{mo} \mathrm{yr}^{-1}$. The vegetative cover in this category is characterised by the removal of the (semi)natural vegetation and replacement with human-facilitated vegetation. The vegetative compound of this category consists of closed to open trees with crown cover between 15 and $100 \%$. By definition, tree height ranges from 3 to $>30 \mathrm{~m}$ in the categories 'Tree cover', 'Mosaic of tree cover and other natural vegetation' and 'Tree cover / Crop land mosaic'. The category 'Shrub cover' represents both closed to open evergreen $(>15 \%)$ and closed to open deciduous. This layer consists of broadleaved closed to open thicket, whereby the crown cover ranges between 15 and $100 \%$ with a height ranging between 0.3 and $5.0 \mathrm{~m}$. All other categories comprise strongly anthropogenic modified areas and were hence classified as unsuitable for the species.

Polygons of protected areas following IUCN criteria (II, IV and VI) were obtained from the World Database on Protected Areas (www.wdpa.org). Category II contains areas focusing on protection and conservation of whole ecosystems, e.g. national parks. Category IV areas are actively managed Habitat and Species Management areas primarily protecting particular species 
and habitats. Protected areas with sustainable use of natural resources are combined under Category VI (Dudley 2008). Protected areas with lower or uncertain protection status were not considered here.

Computation of species distribution models. We used Maxent 3.2.19 (Phillips et al. 2004, 2006; www. cs.princeton.edu/ schapire/maxent/) for SDM computation in order to assess the potential distribution of the tree frogs. This program uses a machine-learning algorithm to compute the likelihood of the species in question occurring at any point in the area of the analysis. It has been shown to reveal better results than other comparable methods such as BIOCLIM, DOMAIN or GARP for predicting the environmental requirements that make up a species range (e.g. Elith et al. 2006, Wisz et al. 2008). The reliability of the results obtained from Maxent models for the spatial distribution of suitable habitat for the species has been confirmed by the outcome of introductions of invasive species outside the native range (Peterson \& Vieglais 2001, Rödder et al. 2008, Rödder 2009, Rödder \& Weinsheimer 2009). Furthermore, and probably more important to this study, it has proven to be highly useful in predicting novel presence localities for poorly known species (Pearson et al. 2007). We conducted Maxent runs using only the climate layer as variables applying the default settings. The logistic output format with suitability values ranging from 0 (unsuitable) to 1 (optimal) (Phillips \& Dudík 2008) was chosen. For each run, Maxent allows us to assess the relative importance of each variable using a jackknife approach and provides a variety of possible thresholds to convert continuously scaled logistic output maps into reasonable presence/absence maps. We applied 2 of these thresholds, i.e. the minimum training presence and the lowest 10 percentile training presence, which are widely used in SDM applications (Liu et al. 2005). Additionally, the output map describing the potential distribution of the species derived from climate was overlaid with the land cover data to exclude areas unsuitable due to microhabitat features.

Maxent allows for testing the model performance by calculation of the Area Under the Curve (AUC), referring to the Receiver Operating Characteristic (ROC) curve (Hanley \& McNeil 1982). In ROCs, the sensitivity values, the true-positive fraction against 1 - specificity and the false-positive fraction for all available probability thresholds are plotted (Fielding \& Bell 1997). This method is recommended for ecological applications because it is nonparametric (Pearce \& Ferrier 2000). Values of AUC range from 0.5 (i.e. random) for models with no predictive ability to 1.0 for models giving perfect predictions. According to the classification of Swets (1988), AUC values $>0.9$ describe model fits that are 'very good' in other words, the modelled distribution of suitable habitat matches the localities of known occurrences that we entered; values $>0.8$ are considered 'good' and values $>0.7$ indicate 'useful' discrimination ability.

\section{RESULTS}

We obtained 'good' AUC values for both species distribution models (Leptopelis ragazzii: $\mathrm{AUC}=0.884 ; \mathrm{L}$. vannutellii: $\mathrm{AUC}=0.883$ ). The minimum Maxent value in the training records of $L$. ragazzii was 0.325 , whereby the lowest $10 \%$ percentile was 0.343 . The minimum Maxent value and the lowest $10 \%$ percentile in the training records of $L$. vannutellii were both 0.329 . The relative variable importance and the results of the jack-knife test of variable importance are provided in Table 1. In L. ragazzii, the environmental variable with the highest gain when used in isolation was 'the mean temperature of the warmest quarter', which therefore appears to provide the most useful information by itself, and was at the same time the environ-

Table 1. Leptopelis ragazzii and L. vanutellii. Relative variable contribution in Maxent models and results of a jack-knife test

\begin{tabular}{|lcc|}
\hline Variable & L. ragazzii & L. vannutellii \\
\hline Variable contribution (\%) & & \\
Annual mean temperature & 0.60 & 0.00 \\
Mean temperature warmest quarter & 89.26 & 0.00 \\
Mean temperature coldest quarter & 0.00 & 1.16 \\
Annual precipitation & 0.17 & 75.46 \\
Precipitation wettest quarter & 8.98 & 0.00 \\
Precipitation driest quarter & 0.99 & 23.38 \\
Training gain with all variables & 0.78 & 0.67 \\
Training gain without... & & \\
Annual mean temperature & 0.78 & 0.67 \\
Mean temperature warmest quarter & 0.74 & 0.67 \\
Mean temperature coldest quarter & 0.78 & 0.66 \\
Annual precipitation & 0.78 & 0.54 \\
Precipitation wettest quarter & 0.73 & 0.67 \\
Precipitation driest quarter & 0.78 & 0.58 \\
Training gain with only... & & \\
Annual mean temperature & 0.65 & 0.00 \\
Mean temperature warmest quarter & 0.72 & 0.00 \\
Mean temperature coldest quarter & 0.61 & 0.00 \\
Annual precipitation & 0.00 & 0.57 \\
Precipitation wettest quarter & 0.08 & 0.13 \\
Precipitation driest quarter & 0.10 & 0.38 \\
\hline
\end{tabular}


mental variable that decreased the gain the most when it was omitted. It therefore appears to include the most information that is not present in the other variables. In L. vannutellii, the same pattern is evident for the 'annual precipitation'.

Fig. 3 shows the remaining suitable vegetation structure and 3 different scenarios of the potential distribution of Leptopelis ragazzii. Fig. 3A illustrates the status of the current vegetation in the investigated area in relation to the distribution area of $L$. ragazzii assumed by Largen \& Schiøtz (2004). Only small parts of this assumed distribution area is covered by undisturbed forest, of which the Harenna Forest (green area on the left side of the map) on the southern slopes of the Bale Mountains makes up the greatest part. Fig. 3B illustrates the predicted potential distribution for $L$. ragazzii from the SDM in Maxent. This model is based only on climate variables without regard to forest cover. When the results from Fig. 3B are trimmed to only include areas with suitable forest cover, Fig. 3C depicts those areas with both a suitable climate and adequate forest cover. We believe this to be the more accurate depiction of available habitat based on the assumption that the species is able to survive in slightly disturbed areas such as 'Tree cover/Crop land mosaic'. If this assumption is correct, its current distribution is limited to the south-western parts of its recognised distribution east of the Rift Valley. Approxi- mately half of that range (Fig. 3C) is situated within the Bale Controlled Hunting Area (IUCN category VI) and small parts in the Bale Wildlife Reserve (IUCN category IV). West of the Rift Valley, our model indicates that $L$. ragazzii may be restricted to small and strongly fragmented relict habitats not covered by any protected area, making it highly vulnerable to further habitat loss. If L. ragazzii is as strictly bound to undisturbed forest habitats as suggested by Largen (1977) and Largen \& Schiøtz (2004), the potential inhabitable area shrinks mostly to a small fragment in the southwest of the Bale Controlled Hunting area (Fig. 3D). Outside that area, the species is likely to become extirpated, since only very small and strongly fragmented habitats remain available.

In contrast, the potential distribution of Leptopelis vannutellii inferred from climate data is still widely covered with undisturbed, connected tree cover, and only scattered areas inside the known distribution of the species are severely degraded (Fig. 4A). Large parts of the northern, eastern and western distribution areas assumed by Largen \& Schiøtz (2004) are climatically suitable for the species (Fig. 4B), but do not exhibit the vegetation preferred by the species. Assuming that this species tolerates slight disturbances, suitable habitats appear in most parts of its expected distribution as well as in scattered parts outside its range, especially in the west and northeast (Fig. 4C).

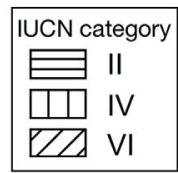

(A) Land cover

$\square$ Tree cover

Natural vegetation mosaic

Shrub cover

Tree cover/

Crop land mosaic

Unsuitable habitats

(B-D) Maxent value

$\square 0.000-0.304$
$\square 0.304-0.400$
$\square 0.400-0.500$
$\square 0.500-0.600$
$\square 0.600-0.700$
$\square 0.700-0.800$
$\square 0.800-0.900$
$\square 0.900-1.000$
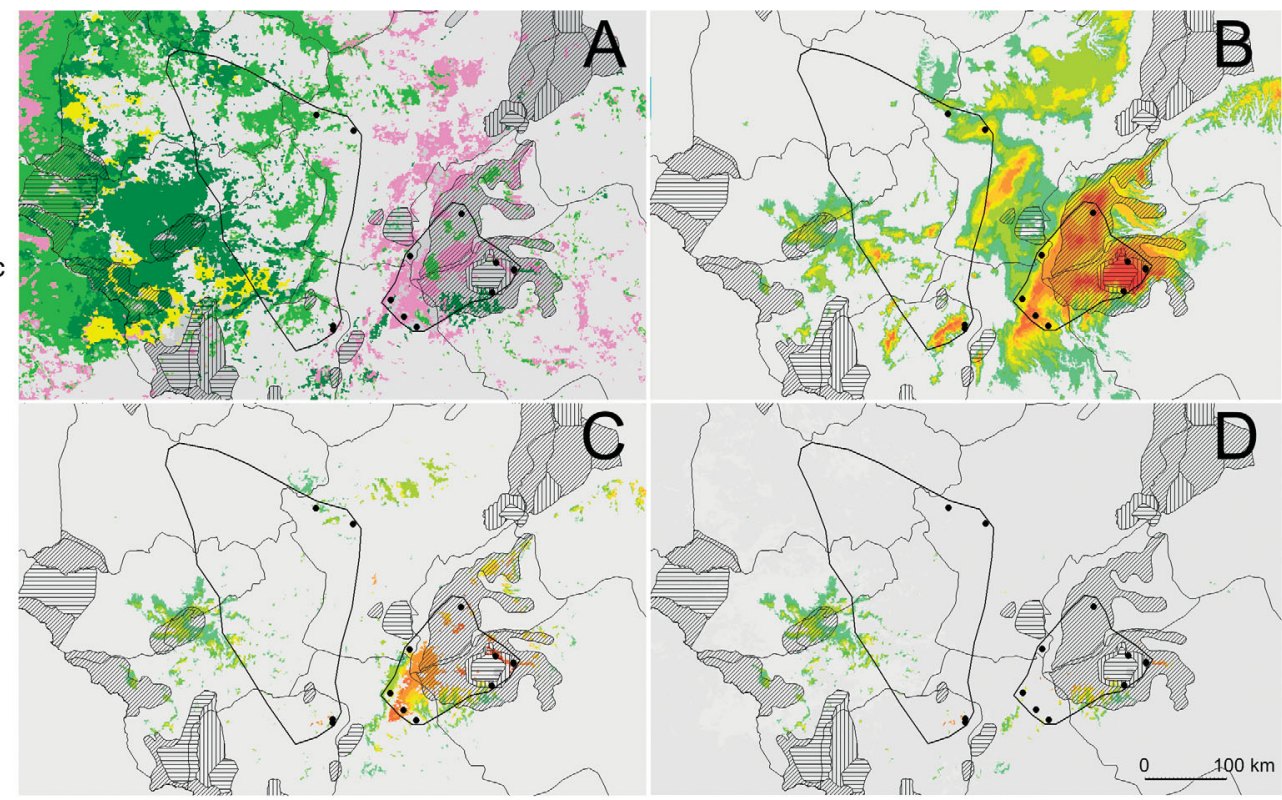

Fig. 3. Leptopelis ragazzii. Assessment (black dots). The distribution of the species assumed by Largen \& Schiøtz (2004) is indicated as black polygons; shaded areas mark protected zones following IUCN criteria. Higher Maxent values suggest higher habitat suitability. (A) Large-scale vegetation map of the region indicating the spatial distribution of suitable habitats according to land cover information. (B) Climatically suitable habitats for L. ragazzii derived from climate variables only. (C) Possible distribution of L. ragazzii assuming both adequate climatic conditions and survival in undisturbed and slightly disturbed habitats and (D) assuming adequate climatic conditions and survival exclusively in undisturbed habitats. IUCN categories as in Fig. 2 


\begin{tabular}{l} 
IUCN category \\
\hline$\square$ IV \\
(A) Land cover \\
$\square$ Tree cover \\
$\square$ Natural vegetation mosaic \\
$\square$ Shrub cover \\
$\square$ Tree cover/ \\
Crop land mosaic \\
$\square$ Unsuitable habitats \\
(B-D) Maxent value \\
$\square 0.000-0.329$ \\
$\square 0.329-0.500$ \\
$\square 0.500-0.600$ \\
$\square 0.600-0.700$ \\
$\square 0.700-0.800$ \\
$\square 0.800-0.900$ \\
$\square 0.900-1.000$
\end{tabular}

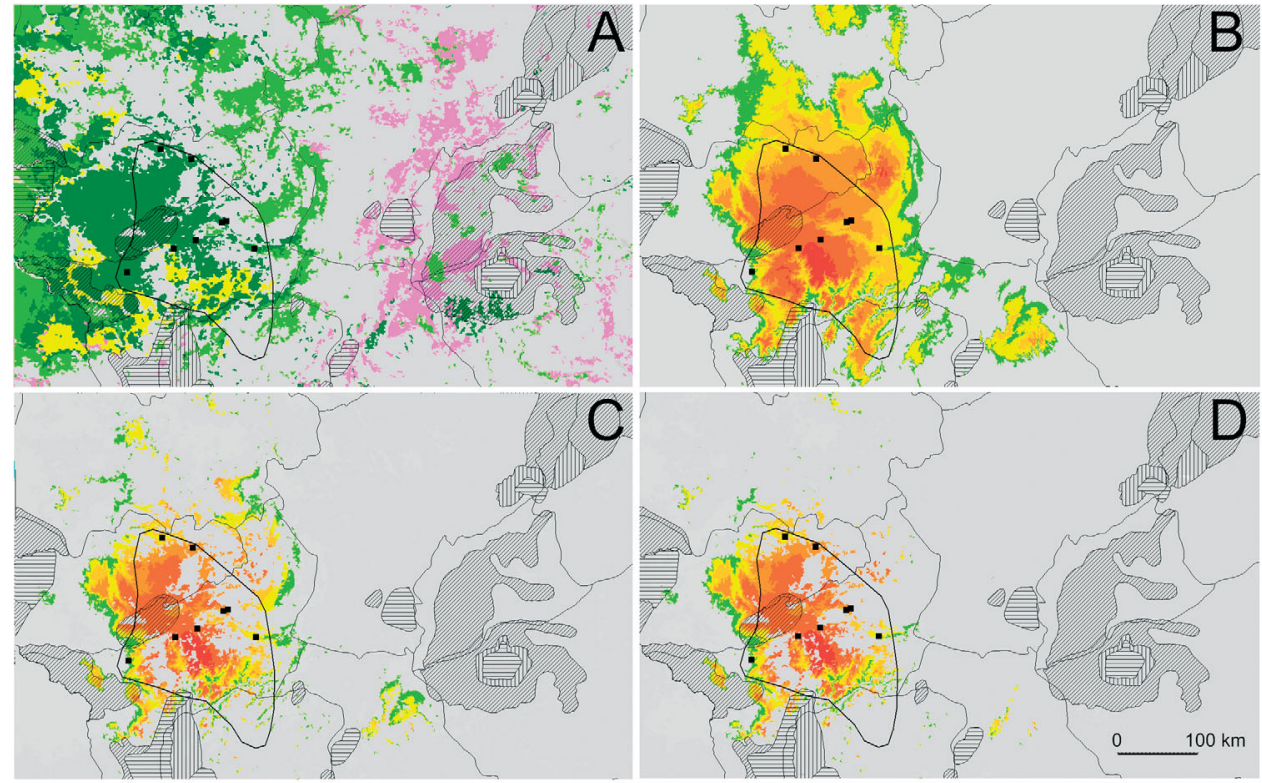

Fig. 4. As in Fig. 3, but for Leptopelis vannutellii

\section{DISCUSSION}

Leptopelis ragazzii is listed as vulnerable in the IUCN Red List of threatened species based on its small range size, estimated at less than $2000 \mathrm{~km}^{2}$, and the fact that this range is strongly fragmented and the extent and quality of its habitat continue to decline (www.redlist.org). Our results indicate that the previously assumed distribution of $L$. ragazzii west of the Rift valley is much smaller than assumed by Largen \& Schiøtz (2004). Inappropriate climate as well as natural boundaries through unsuitable habitat and anthropogenic habitat destruction limit its range to a few small isolated areas. From the results of this study, it is clear that only protected forest areas such as situated around the Bale Mountains can assure a long-term survival of this species both in terms of the suitable climate conditions and forest cover. Bale Mountains National Park (IUCN Category II), the adjacent Bale Wildlife Reserve (IUCN Category IV) and the Bale Controlled Hunting Area (IUCN Category VI) are the only protected areas within the range of this species, but these areas contain very few suitable habitats based on our findings. This is especially critical, as most of these remaining habitats lie at the edge of the protected zones where human population growth is higher than in other rural areas (Wittemyer et al. 2008). Sadly, most of the voucher records of L. ragazzii available in the literature are more than $30 \mathrm{yr}$ old, and it is uncertain if the species still exists at the sites where it had been collected in the past. Since L. ragazzii seems to be incapable of adapting to disturbed habitats, it is likely that the last refuges of this species will disappear in the near future unless those areas predicted as suitable habitat can be protected from human encroachment. Only inaccessible forest remnants, usually along steep-sided valleys, offer an opportunity to retreat (Largen 1977).

Much like Leptopelis ragazzii, the IUCN lists L. vannutellii as vulnerable with a decreasing population trend. This species inhabits a relatively large forest fragment west of the Rift Valley and seems to be less immediately threatened through habitat loss than $L$. ragazzii because a higher portion of the climatically suitable area is still covered by undisturbed forest. Assuming that $L$. vannutellii is equally intolerant to any habitat disturbance as $L$. ragazzii, the predicted potential distribution from this study matches closely to the distribution assumed by Largen \& Schiøtz (2004), and may even range farther west (Fig. 4C). Based on the suitability of climate and habitat variables from this study, the occurrence of additional, thus far undetected populations of this species in that area is highly likely. However, it is also likely that the status of $L$. vannutellii will degrade seriously in the future, as huge parts of the remaining forest are unprotected and therefore at risk. Only one relatively small, protected zone (controlled hunting area of Mizan-Teferi, IUCN category IV) is contained within its currently known distribution.

In addition to the 2 Leptopelis spp. considered in this study, L. susanae, another endangered species, is also found within these mountain ranges at elevations between 2600 and 2700 m (Largen, 1977) in the Gughe Mountains. Though once known from only 2 localities, 
in our research for this study we were informed of 2 further occurrences in the Bale Mountains (S. Lötters pers. comm.), which increases the overall distribution of the species to the north and gives hope of finding more populations of all 3 species. Similar to L. ragazzii and $L$. vannutellii, L. susanae appears to rely on undisturbed, dense mountain forest and only survives in these forests along streams in inaccessible areas. Unfortunately, locality data of L. susanae are too limited and do not allow computing a reasonable SDM. Even without creating SDMs of the potential distribution of this third species, we do know that these 2 mountainous areas, Gughe and Bale, are separated by heavily degraded areas, which would potentially limit gene flow between these relic populations. The fragmented distribution of habitat is likely to lead to low genetic diversity and potential population extinctions, as seen in a number of studies of endangered species in fragmented refugia (e.g. see Habel et al. 2009 and references therein).

\section{CONCLUSIONS}

This study highlights the fact that even though Leptopelis ragazzii and L. susanae are theoretically protected by several reserves, their populations seem to be extremely vulnerable to the threats of habitat loss and habitat fragmentation. Enlarged, connected protected areas centred on the environmental and ecological requirements of these species are needed to ensure the survival of the species. In contrast to the 2 montane forest endemics, the potential distribution of the submontane L. vannutellii is only marginally covered by protected areas, yet a greater extent of its predicted range includes both the ecological and environmental conditions that it needs for survival. For all species, further field studies are urgently needed to gather data about the remaining population size, genetic diversity and population structure, distribution boundaries of all populations, and current threats. Although the Maxent models of the distribution of suitable climate conditions for each species have little predictive power due to the small sample sizes of these rare species, nevertheless, as suggested by Pearson et al. (2007), niche models derived from small numbers of occurrence records are effective as guidelines for further field surveys to accelerate the discovery of unknown populations and species.

A new wave of scientific research into Ethiopian amphibians is focusing on the identification, distribution, conservation and other biological aspects of these little known species with a focus on the forests in the Bale Mountains and the southwest highlands across the East African Rift Valley (A. A. Mengistu unpubl.) with an aim to identify species in need of prioritisation for conservation measures. In 2006, geographic and biological data were collected from over 350 amphibian specimens (kept in ZNHM/AAU, Addis Ababa; B. Zimkus unpubl.). Additional data from 2006 and 2008 on the distributions and genetic relationships at the species and population level are now being processed (S. Loader, A. A. Mengistu and S. Saber unpubl.). The biogeographic data being collected from such ongoing field work and predictions of suitable habitats such as those made in this study offer 2 powerful tools for conservation biology: (1) ongoing and upcoming field work can use the Maxent prediction of suitable habitat as a tool to concentrate on potentially suitable habitats, and (2) findings from new field data and systematics can in turn be used to evaluate the accuracy of the current prediction.

Acknowledgements. We thank W. Böhme, S. Lötters and S. Schick who helped us with partly unpublished distribution records, literature and photos. M. Mahony, V. Wasonga and 2 anonymous reviewers greatly improved the manuscript. This work was partly funded by the 'Graduiertenförderung des Landes Nordrhein-Westfalen' and the research initiative of the Ministry of Education, Science, Youth and Culture of Rhineland-Palatinate (Germany) ('Die Folgen des Global Change für Bioressourcen, Gesetzgebung und Standardsetzung').

\section{LITERATURE CITED}

AmphibiaWeb (2009) Information on amphibian biology and conservation. University of California, Berkeley, CA. Available at: www.amphibiaweb.org (accessed Feb 13, 2009)

$>$ Beaumont LJ, Hughes L, Poulsen M (2005) Predicting species distributions: use of climatic parameters in BIOCLIM and its impact on predictions of species' current and future distributions. Ecol Model 186:251-270

> Carnaval AC, Moritz C (2008) Historical climate modelling predicts patterns of current biodiversity in the Brazilian Atlantic forest. J Biogeogr 35:1187-1201

$>$ Dessie G, Christiansson C (2008) Forest decline and its causes in the south-central Rift Valley of Ethiopia: human impact over a one hundred year perspective. Ambio 37:263-271

> Dessie G, Kleman J (2007) Pattern and magnitude of deforestation in the south central Rift Valley region of Ethiopia. Mt Res Dev 27:162-168

Dudley N (ed) (2008) Guidelines for applying protected area management categories. IUCN, Gland

Elith J, Graham CH, Anderson RP, Dudik M and others (2006) Novel methods improve prediction of species' distributions form occurrence data. Ecography 29:129-151

> Evangelista P, Norman J, Berhanu L, Kumar S, Alley N (2008) Predicting habitat suitability for the endemic mountain nyala (Tragelaphux buxtoni) in Ethiopia. Wildl Res 35: 409-416

FAO (Food and Agriculture Organization) (2000) Global forest resources assessment. FAO, Rome

Fielding AH, Bell JF (1997) A review of methods for the assessment of prediction errors in conservation presence/ absence models. Environ Conserv 24:38-49 
Frost DR (2009) Amphibian species of the world: an online reference. V5.1 Electronic database. American Museum of Natural History, New York. Available at: http://research. amnh.org/herpetology/amphibia/index.html

Habel JC, Augenstein A, Nève G, Rödder D, Assmann T (2009) Population genetics and ecological niche modelling reveal high fragmentation and potential future extinction of the endangered relict butterfly Lycaena helle. In: Habel JC, Assmann T (eds) Relict species: phylogeography and conservation biology. Springer, Berlin

Hanley JA, McNeil BJ (1982) The meaning of the use of the area under a receiver operating characteristic (ROC) curve. Radiology 143:29-36

Heikkinen RK, Luoto M, Araújo MB, Virkkala R, Thuiller W, Sykes MT (2006) Methods and uncertainties in bioclimatic envelope modelling under climate change. Prog Phys Geogr 30:751-777

Hijmans RJ, Schreuder J, De la Cruz J, Guarino L (1999) Using GIS to check co-ordinates of genebank accessions. Genet Resour Crop Evol 46:291-296

Hijmans RJ, Cruz JM, Rojas E, Guarino L (2001) DIVA-GIS, version 1.4. A geographic information system for the management and analysis of genetic resources data. Manual. International Potato Center and International Plant Genetic Resources Institute, Lima

Hijmans RJ, Cameron SE, Parra JL, Jones PG, Jarvis A (2005a) Very high resolution interpolated climate surfaces for global land areas. Int J Climatol 25:1965-1978

Hijmans RJ, Guarino L, Jarvis A, O'Brien R and others (2005b) DIVA-GIS Version 5.2 Manual. International Potato Center, Lima

- Hutchinson MF (1995) Interpolating mean rainfall using thin plate smoothing splines. Int J Geogr Inf Syst 9:385-403

Hutchinson MF (2004) Anusplin version 4.3. Centre for Resource and Environment Studies, The Australian National University, Canberra

IUCN (International Union for Conservation of Nature and Natural Resources) (ed) (2009) IUCN Red List of threatened species. Version 2009.1. Available at: www.iucnredlist.org

Largen MJ (1977) The status of the genus Leptopelis (Amphibia: Anura: Hyperolidae) in Ethiopia, including description of two new species. Monit Zool Ital 5:85-136

Largen MJ, Schiøtz A (2004) Leptopelis ragazzii. In: IUCN (ed) 2008 IUCN Red List of threatened species. Available at: http://iucnredlist.org/apps/redlist/details/56279/0

Liu C, Pam M, Dawson TP, Pearson RG (2005) Selecting thresholds of occurrence in the prediction of species distributions. Ecography 28:385-393

McCann JC (1999) Green land, brown land, black land: an environmental history of Africa. 1800-1990. James Currey, Oxford

Nix H (1986) A biogeographic analysis of Australian elapid snakes. In: Longmore R (ed) Atlas of elapid snakes of Australia. Bureau of Flora and Fauna, Canberra, p 4-15

Pearce J, Ferrier S (2000) An evaluation of alternative algorithms for fitting species distribution models using logistic regression. Ecol Model 128:127-147

Editorial responsibility: Michael Mahony,

Callaghan, New South Wales, Australia
Pearson RG, Raxworthy CJ, Nakamura M, Peterson AT (2007) Predicting species distributions from small numbers of occurrence records: a test case using cryptic geckos in Madagascar. J Biogeogr 34:102-117

> Peterson AT, Vieglais DA (2001) Predicting species invasions using ecological niche modeling: new approaches from bioinformatics attack a pressing problem. Bioscience 51:363-371

Phillips SJ, Dudík M (2008) Modeling of species distributions with Maxent: new extensions and comprehensive evaluation. Ecography 31:161-175

Phillips SJ, Dudík M, Shapire RE (2004) A maximum entropy approach to species distribution modeling. In: Brodley CE (ed) Proc 21st Int Conf Machine Learning, Jul 4-8 2004, Banff. ACM Press, New York, p 655-662

> Phillips SJ, Anderson RP, Schapire RE (2006) Maximum entropy modeling of species geographic distributions. Ecol Model 190:231-259

Reusing M (1998) Monitoring of natural high forest resources in Ethiopia. Ministry of Agriculture, Addis Abeba

Rödder D (2009) 'Sleepless in Hawaii' — does anthropogenic climate change enhance ecological and socioeconomic impacts of the alien invasive Eleutherodactylus coqui Thomas, 1966 (Anura: Eleutherodactylidae)? Northwest J Zool 5:16-25

Rödder D, Dambach J (2009) Bioclimatic models as predictive GIS tools for the identification of potential refuges and possible migration pathways. In: Habel JC, Assmann T (eds) Relict species: phylogeograhy and conservation biology. Springer, Berlin

> Rödder D, Weinsheimer F (2009) Will future anthropogenic climate change increase the potential distribution of the alien invasive Cuban treefrog (Anura: Hylidae)? J Nat Hist 43:1207-1217

Rödder D, Solé M, Böhme W (2008) Predicting the potential distribution of two alien invasive housegeckos (Gekkonidae: Hemidactylus frenatus, Hemidactylus mabouia). Northwest J Zool 4:236-246

Schick S (2005) Eine batrachologische Erkundungsreise in das äthiopische Hochland. Amphibia 4:31-34

Stuart SN, Chanson JS, Cox NA, Young BE, Rodrigues ASL, Fischman DL, Waller RW (2004) Status and trends of amphibian declines and extinctions worldwide. Science 306:1783-1786

Stuart S, Hoffmann M, Chanson J, Cox N, Berridge R, Ramani P, Young B (2008) Threatened amphibians of the world. Lynx Edicions, Barcelona; IUCN, Gland; Conservation International, Arlington, VA

Swets JA (1988) Measuring the accuracy of diagnostic systems. Science 240:1285-1293

Wisz MS, Hijmans RJ, Peterson AT, Graham CH, Guisan A, and the NPSDW Group (2008) Effects of sample size on the performance of species distribution models. Divers Distrib 14:763-773

Wittemyer G, Elsen P, Bean W, Burton A, Brashares J (2008) Accelerated human population growth at protected area edges. Science 321:123-126

Submitted: May 27, 2009; Accepted: August 27, 2009

Proofs received from author(s): December 23, 2009 